\title{
A novel real-time PCR assay for quantitative detection of Campylobacter fetus based on ribosomal sequences
}

\author{
Gregorio Iraola ${ }^{1,2}$, Ruben Pérez ${ }^{1}$, Laura Betancor ${ }^{4}$, Ana Marandino ${ }^{1}$, Claudia Morsella ${ }^{3}$, Alejandra Méndez ${ }^{3}$,
} Fernando Paolicchi ${ }^{3}$, Alessandra Piccirillo ${ }^{5}$, Gonzalo Tomás ${ }^{1}$, Alejandra Velilla ${ }^{3}$ and Lucía Calleros ${ }^{1 *}$

\begin{abstract}
Background: Campylobacter fetus is a pathogen of major concern for animal and human health. The species shows a great intraspecific variation, with three subspecies: C. fetus subsp. fetus, C. fetus subsp. venerealis, and C. fetus subsp. testudinum. Campylobacter fetus fetus affects a broad range of hosts and induces abortion in sheep and cows. Campylobacter fetus venerealis is restricted to cattle and causes the endemic disease bovine genital campylobacteriosis, which triggers reproductive problems and is responsible for major economic losses. Campylobacter fetus testudinum has been proposed recently based on genetically divergent strains isolated from reptiles and humans. Both C. fetus fetus and C. fetus testudinum are opportunistic pathogens for immune-compromised humans. Biochemical tests remain as the gold standard for identifying C. fetus but the fastidious growing requirements and the lack of reliability and reproducibility of some biochemical tests motivated the development of molecular diagnostic tools. These methods have been successfully tested on bovine isolates but fail to detect some genetically divergent strains isolated from other hosts. The aim of the present study was to develop a highly specific molecular assay to identify and quantify $C$. fetus strains.

Results: We developed a highly sensitive real-time PCR assay that targets a unique region of the $165 \mathrm{rRNA}$ gene. This assay successfully detected all $C$. fetus strains, including those that were negative for the cstA gene-based assay used as a standard for molecular $C$. fetus identification. The assay showed high specificity and absence of cross-reactivity with other bacterial species. The analytical testing of the assay was determined using a standard curve. The assay demonstrated a wide dynamic range between $10^{2}$ and 107 genome copies per reaction, and a good reproducibility with small intra- and inter-assay variability.
\end{abstract}

Conclusions: The possibility to characterize samples in a rapid, sensitive and reproducible way makes this assay a good option to establish a new standard in molecular identification and quantification of $C$. fetus species.

Keywords: Campylobacter fetus, Molecular detection, Real-time PCR

\section{Background}

Members of the genus Campylobacter are gram-negative epsilon-proteobacteria highly adapted to vertebrate hosts. Most species are pathogens of a wide range of livestock species and have extensive reservoirs in wildlife [1-3].

The species Campylobacter fetus shows a remarkable level of intraspecific variation, with three subspecies: $C$.

\footnotetext{
* Correspondence: calleros@fcien.edu.uy

'Sección Genética Evolutiva, Facultad de Ciencias, Iguá 4225, Montevideo

11400, Uruguay

Full list of author information is available at the end of the article
}

fetus subsp. fetus, C. fetus subsp. venerealis, and C. fetus subsp. testudinum. Campylobacter fetus fetus and $C$. fetus venerealis are classified on the basis of their mechanisms of transmission, clinical presentations and two key biochemical tests (tolerance to glycine and $\mathrm{H}_{2} \mathrm{~S}$ production) [4, 5]. Campylobacter fetus fetus infects the intestinal tract of several mammalian species and induces abortion in cattle and sheep $[2,5,6]$. In humans, it is an opportunistic pathogen that mainly infects immunecompromised patients [7, 8]. Campylobacter fetus venerealis is a cattle-restricted pathogen with tropism for 
genital tissues and is the etiological agent of bovine genital campylobacteriosis (BGC), a serious reproductive disease that causes infertility and abortion [9]. $C$. fetus venerealis includes a variant, namely $C$. fetus venerealis biovar intermedius that reacts differently to the $\mathrm{H}_{2} \mathrm{~S}$ test and also causes BGC [5]. Campylobacter fetus testudinum has been proposed recently to cluster some reptilian and human strains of putative reptilian origin on the basis of notorious genetic divergence from C. fetus fetus and C. fetus venerealis [10].

Biochemical tests remain as the gold standard for identifying C. fetus and differentiating between C. fetus fetus and $C$. fetus venerealis, but the fastidious growth requirements and the lack of reliability and reproducibility of some assays [11], due in part to the genetic heterogeneity of some strains, motivated the development of alternative diagnostic methods.

Several studies have endeavored in determining the suitability of different genetic methods for identifying the species C. fetus using end-point PCRs. In particular, the multiplex-PCR assay designed by Hum et al. [12] has been vastly used for species identification. Detection of C. fetus in this assay is achieved using PCR primers that target signature regions of the cstA gene, and C. fetus venerealis identification is based on the parA gene. However, genetic divergence in the $c s t A$ gene could prevent their detection by this assay, as occur in reptilian strains, and thus fails as a general diagnostic tool to identify the species [10].

Other assays for $C$. fetus identification were later designed to target additional genes, like cpn60, which encodes the universal $60-\mathrm{kDa}$ chaperonin, and nahE, which encodes a sodium/hydrogen exchanger protein [13, 14]. The cpn60 and nahE gene-based methods have been updated to real-time PCR assays using different technologies [14-17]. Both real-time assays have been designed to detect $C$. fetus on bovine isolates, and successfully tested on this kind of samples, but may fail to detect some genetically divergent strains, particularly of reptilian origin, which have distinctive nucleotide variants in many genes. Therefore, detection of $C$. fetus can be improved by developing new real-time PCR assays able to detect strains from all subspecies and hosts. These assays should be designed to target highly stable genomic regions that are characteristic for the species. Ribosomal genes are one of the most common DNA regions used to design PCR assays for the identification and detection of microorganisms. The $16 \mathrm{~S}$ rRNA gene-targeted molecular tools are widely used as its variability has been thoroughly described in all Campylobacter species [18-23]. The sequence of the $16 \mathrm{~S}$ rRNA gene is species-specific within the genus and $C$. fetus has several unique nucleotide markers [24, 25]. Moreover, ribosomal genes are homogeneous for $C$. fetus subspecies and have three identical copies per genome allowing a better detection. Despite the obvious advantages of these genes, so far, there is not a real-time PCR assay targeting ribosomal sequences for the specific detection of $C$. fetus.

The aim of the present study was to develop a highly sensitive real-time PCR assay, to detect and quantify $C$. fetus strains.

\section{Results}

Strains were assigned to C. fetus and its subspecies using standard bacteriological methods (Table 1). Additionally, we performed the molecular characterization in the same collection of strains (Table 1). The results of bacteriological and molecular classification do not always match, particularly at the subspecies level One bovine (INTA 89/222) and the reptilian isolate (RA8/Italy/2011) were phenotypically identified as $C$. fetus but were negative for the $c s t A$ gene amplicon that is currently used as a marker for $C$. fetus. The bovine isolate was positive for the subspecies (C. fetus venerealis) markers of both tests and the reptilian isolate was negative. The assignment of these isolates to the species $C$. fetus was confirmed by sequencing a fragment of the $16 S$ rRNA gene, which unequivocally discriminates between Campylobacter species and from other bacterial species [21, 24].

The $16 \mathrm{SPb}$ probe is species specific and has a minimum of one mismatch with a single sequence from $C$. hyointestinalis, and a maximum of nine differences with other Campylobacter species (e.g. C. rectus and C. showae). The forward primer's sequence is species specific and has a minimum of one and a maximum of four mismatches with other Campylobacter species (Figs. 1 and 2, Additional file 1). The reverse primer's sequence is identical in some Campylobacter species but has one or two differences with others. The combination of primers and probe only matches perfectly with the $16 S \mathrm{rRNA}$ gene of C. fetus.

All PCR reactions using template DNA from C. fetus fetus, $C$. fetus venerealis, C. fetus venerealis bv. intermedius, and $C$. fetus testudinum yielded a VIC signal corresponding to the C. fetus-specific probe. This result indicates a $100 \%$ clinical sensitivity and 95\% confidence interval of $94-100 \%$ (Clopper-Pearson interval).

The analytical performance of the assay was determined using a standard curve (Fig. 3). The linear dynamic range of the assay was established between $10^{2}$ and $10^{7}$ genome copies per reaction. The amplification efficiency and the coefficient of determination $\left(R^{2}\right)$ were $93 \%$ and 0.9973 , respectively. Intra- and inter-assay reproducibility was calculated using the coefficient of variation $(\mathrm{CV})$, which showed considerable low values, being the highest $2.19 \%$ (Table 2).

No fluorescent signal was observed using template DNA from non-C. fetus bacterial species used as negative controls (i.e. C. geochelonis, C. hyointestinalis, C. jejuni, C. coli and C. sputorum). This result corresponds to a clinical 
Table 1 Isolates analyzed, discriminated by host, source, country and year of isolation

\begin{tabular}{|c|c|c|c|c|c|c|c|c|}
\hline Isolate & Host & Source & Country & Year & Phenotypic typing ${ }^{a}$ & Multiplex PCR A ${ }^{b}$ & Multiplex PCR B ${ }^{c}$ & Real-time PCR \\
\hline A28 & Bovine & $\mathrm{U}$ & Australia & 1978 & Cff & Cff & Cff & + \\
\hline 063 & Bovine & Prepuce & Uruguay & 1980 & Cff & Cff & Cff & + \\
\hline 0835 & Bovine & $U$ & Uruguay & $U$ & Cff & $\mathrm{Cfv}$ & Cff & + \\
\hline F106 & Bovine & $U$ & Uruguay & $U$ & Cff & Cff & Cff & + \\
\hline 71098 & Bovine & Fetal abomasal content & Uruguay & 1998 & Cff & Cff & Cff & + \\
\hline INTA 97/C1N3 ${ }^{d}$ & Bovine & Vaginal mucus & Argentina & 1997 & Cff & $\mathrm{Cff}$ & Cff & + \\
\hline INTA 04/554 & Bovine & Fetal abomasal content & Argentina & 2004 & Cff & Cff & Cff & + \\
\hline INTA 90/189 & Bovine & Fetal lung & Argentina & 1990 & Cff & Cfv & Cfv & + \\
\hline INTA 89/222 & Bovine & Prepuce & Argentina & 1989 & Cff & No Cf/Cfv & No Cf/Cfv & + \\
\hline INTA 01/165 & Bovine & Vaginal mucus & Argentina & 2001 & Cff & Cff & Cff & + \\
\hline INTA 12/218 & Bovine & Fetal abomasal content & Argentina & 2012 & Cff & Cfv & $\mathrm{Cfv}$ & + \\
\hline INTA 99/801 & Bovine & Prepuce & Argentina & 1999 & Cff & Cff & Cff & + \\
\hline INTA 01/064 & Bovine & Vaginal mucus & Argentina & 2001 & Cff & Cff & Cff & + \\
\hline INTA 04/875 & Bovine & Vaginal mucus & Argentina & 2004 & Cff & Cff & Cff & + \\
\hline INTA 08/328 & Bovine & Fetal lung & Argentina & 2008 & Cff & Cff & Cff & + \\
\hline INTA 05/622 & Bovine & Fetal abomasal content & Argentina & 2005 & Cff & Cff & Cfv & + \\
\hline INTA 11/262 & Bovine & Fetal abomasal content & Argentina & 2011 & Cff & $\mathrm{Cfv}$ & Cfv & + \\
\hline INTA 11/295 & Bovine & Fetal abomasal content & Argentina & 2011 & Cff & Cfv & Cfv & + \\
\hline INTA 11/685A & Bovine & Vaginal mucus & Argentina & 2011 & Cff & Cfv & Cff & + \\
\hline INTA 11/685B & Bovine & Fetal abomasal content & Argentina & 2011 & Cff & $\mathrm{Cfv}$ & Cff & + \\
\hline INTA 11/677 & Bovine & Fetal abomasal content & Argentina & 2011 & Cff & Cff & Cff & + \\
\hline INTA 11/501 & Bovine & Vaginal mucus & Argentina & 2011 & Cff & $\mathrm{Cff}$ & Cff & + \\
\hline INTA 11/408 & Bovine & Fetal abomasal content & Argentina & 2011 & Cff & Cff & Cff & + \\
\hline INTA 11/356 & Bovine & Fetal abomasal content & Argentina & 2011 & Cff & Cff & Cfv & + \\
\hline INTA 11/360 & Bovine & Fetal lung & Argentina & 2011 & Cff & $C f v$ & Cfv & + \\
\hline NCTC10354 & Bovine & U & England & 1962 & $\mathrm{Cfv}$ & $\mathrm{Cff}$ & Cfv & + \\
\hline D78 & Bovine & $U$ & Australia & 1978 & Cfv & Cfv & Cfv & + \\
\hline 660 & Bovine & Fetal abomasal content & Uruguay & 2010 & Cfv & $\mathrm{Cfv}$ & Cfv & + \\
\hline 3726 & Bovine & Fetal abomasal content & Uruguay & 2010 & $\mathrm{Cfv}$ & $\mathrm{Cfv}$ & Cfv & + \\
\hline 2733 & Bovine & Fetal abomasal content & Uruguay & 2006 & $\mathrm{Cfv}$ & $\mathrm{Cfv}$ & Cfv & + \\
\hline 2740 & Bovine & Fetal abomasal content & Uruguay & 2006 & Cfv & $C f v$ & Cfv & + \\
\hline MCR03 & Bovine & Prepuce & Uruguay & 2009 & $\mathrm{Cfv}$ & $\mathrm{Cfv}$ & Cfv & + \\
\hline 3837 & Bovine & Fetal abomasal content & Uruguay & 2010 & $\mathrm{Cfv}$ & $C f v$ & Cfv & + \\
\hline 1198 & Bovine & $U$ & Uruguay & $U$ & $\mathrm{Cfv}$ & Cff & Cfv & + \\
\hline 3598 & Bovine & $U$ & Uruguay & $U$ & Cfv & Cff & Cfv & + \\
\hline 2432 & Bovine & $U$ & Uruguay & 2010 & Cfv & $\mathrm{Cfv}$ & Cfv & + \\
\hline $2370 P$ & Bovine & Fetal abomasal content & Uruguay & 2011 & $\mathrm{Cfv}$ & $\mathrm{Cfv}$ & Cfv & + \\
\hline $2374 C$ & Bovine & Fetal abomasal content & Uruguay & 2011 & $\mathrm{Cfv}$ & $\mathrm{Cfv}$ & $\mathrm{Cfv}$ & + \\
\hline $27460 P$ & Bovine & Fetal abomasal content & Uruguay & 2011 & Cfv & Cfv & Cfv & + \\
\hline INTA $97 / 608^{d}$ & Bovine & Placenta & Argentina & 1997 & $\mathrm{Cfv}$ & $\mathrm{Cfv}$ & $\mathrm{Cfv}$ & + \\
\hline INTA 83/371 & Bovine & Vaginal mucus & Argentina & 1983 & $\mathrm{Cfv}$ & $\mathrm{Cfv}$ & Cfv & + \\
\hline INTA 90/264 & Bovine & Fetal abomasal content & Argentina & 1990 & $\mathrm{Cfv}$ & Cff & Cfv & + \\
\hline INTA 05/355 & Bovine & Fetal abomasal content & Argentina & 2005 & Cfv & $\mathrm{Cfv}$ & Cfv & + \\
\hline INTA 95/258 & Bovine & Vaginal mucus & Argentina & 1995 & Cfv & Cff & Cfv & + \\
\hline
\end{tabular}


Table 1 Isolates analyzed, discriminated by host, source, country and year of isolation (Continued)

\begin{tabular}{|c|c|c|c|c|c|c|c|c|}
\hline INTA 08/382 & Bovine & Fetal abomasal content & Argentina & 2008 & $\mathrm{Cfv}$ & $\mathrm{Cff}$ & Cfv & + \\
\hline 021 & Bovine & U & Australia & 1978 & Cfvi & $\mathrm{Cfv}$ & $C f v$ & + \\
\hline INTA 98/BL472 & Bovine & Fetal abomasal content & Argentina & 1998 & Cfvi & $\mathrm{Cfv}$ & $\mathrm{Cfv}$ & + \\
\hline INTA 99/541 & Bovine & Prepuce & Argentina & 1999 & Cfvi & Cff & $C f v$ & + \\
\hline INTA 97/384 & Bovine & Fetal abomasal content & Argentina & 1997 & Cfvi & Cff & $C f v$ & + \\
\hline INTA 98/472 & Bovine & Fetal abomasal content & Argentina & 1998 & Cfvi & $C f v$ & $C f v$ & + \\
\hline INTA 00/305 & Bovine & Fetal abomasal content & Argentina & 2000 & Cfvi & Cff & Cfv & + \\
\hline INTA 02/146 & Bovine & Vaginal mucus & Argentina & 2002 & Cfvi & $C f v$ & $C f v$ & + \\
\hline INTA 03/596 & Bovine & Fetal abomasal content & Argentina & 2003 & Cfvi & Cff & Cff & + \\
\hline INTA 07/379 & Bovine & Fetal abomasal content & Argentina & 2007 & Cfvi & Cff & $C f v$ & + \\
\hline INTA 06/341 & Bovine & Fetal lung & Argentina & 2006 & Cfvi & $C f v$ & Cfv & + \\
\hline H1-UY & Human & Blood & Uruguay & 2013 & Cf & Cff & $\mathrm{Cff}$ & + \\
\hline $\mathrm{HC}$ & Human & Blood & Uruguay & 2014 & Cf & Cff & Cff & + \\
\hline $70 \mathrm{~L}$ & Human & Cerebrospinal fluid & Uruguay & 2014 & $\mathrm{Cf}$ & $\mathrm{Cff}$ & Cff & + \\
\hline $70 \mathrm{H}$ & Human & Blood & Uruguay & 2014 & Cf & Cff & $\mathrm{Cff}$ & + \\
\hline RA8/Italy/2011 & Turtle & Cloaca & Italy & 2011 & $\mathrm{Cft}$ & No Cf & No Cf & + \\
\hline $\mathrm{RC7}$ & Turtle & Cloaca & Italy & 2011 & C. geochelonis & No Cf & No Cf & - \\
\hline $\mathrm{RC} 11$ & Turtle & Cloaca & Italy & 2011 & C. geochelonis & No Cf & No Cf & - \\
\hline $\mathrm{RC} 20$ & Turtle & Cloaca & Italy & 2011 & C. geochelonis & No Cf & No Cf & - \\
\hline INTA 08/209 & Bovine & Prepuce & Argentina & 2008 & C. sputorum & No Cf & No Cf & - \\
\hline $\mathrm{CCHB} 41$ & Human & Feces & Uruguay & 2010 & C. coli & No Cf & No Cf & - \\
\hline CjHB32 & Human & Feces & Uruguay & 2010 & C. jejuni & No Cf & No Cf & - \\
\hline CjCP3 & Chicken & Cecal content & Uruguay & 2010 & C. jejuni & No Cf & No Cf & - \\
\hline СcCP60 & Chicken & Cecal content & Uruguay & 2009 & C. coli & No Cf & No Cf & - \\
\hline INTA 99/243 & U & Vaginal mucus & Argentina & 1999 & C. hyointestinalis & No Cf & No Cf & - \\
\hline NCTC 11562 & Pork & U & England & 1983 & C. hyointestinalis & No Cf & No Cf & - \\
\hline
\end{tabular}

Cft Campylobacter fetus subsp. testudinum, Cff Campylobacter fetus subsp. fetus, Cfv Campylobacter fetus subsp. venerealis, Cfvi Campylobacter fetus subsp. venerealis biovar intermedius, Cf Campylobacter fetus, $U$ unknown, ND not determined

${ }^{a}$ in C. fetus, glycine tolerance and $\mathrm{H} 2 \mathrm{~S}$ production, see text for details

${ }^{\mathrm{b}}$ As described in Hum et al. [12]

${ }^{\mathrm{C}}$ As described in Iraola et al. [41]

${ }^{d}$ These strains were assayed both starting from a resuspended culture and directly from bovine samples of placenta or vaginal mucus, without a previous isolation step

specificity of 100 and a 95\% confidence interval of 59100\% (Clopper-Pearson interval).

\section{Discussion}

Campylobacter fetus is a pathogen of great relevance for the cattle industry and public health. It is mandatory to report the presence $C$. fetus venerealis to the World Organization for Animal Health (OIE). In humans it is necessary to detect this opportunistic pathogen to achieve a better treatment and for epidemiological surveys. Detection of $C$. fetus in humans is difficult because both C. fetus fetus and C. fetus testudinum are potential pathogens and well-established methods would fail to detect strains of reptilian origin [10]. Therefore, cost-effective, automated and straightforward tools for the unambiguous identification of C. fetus are of paramount importance.
Bacteriological analysis, like culture isolation and biochemical tests, are well standardized and extensively used but challenging by the slow growing and few differential phenotypic properties of C. fetus [26]. These methods are also laborious and time-consuming, a disadvantage when processing samples at large-scale or delivering a fast diagnosis. To improve the quality and complement the gold-standard bacteriological methods for C. fetus detection, some end-point PCR methods have been designed based on the presence of speciesspecific amplicons [12, 27-29]; these assays fulfill various criteria such as accuracy, high detection probability and well-standardized protocols for its application and interpretation. Real-time PCR methods have been also designed with the same purpose [14-17] and have provided additional technical improvements to C. fetus 


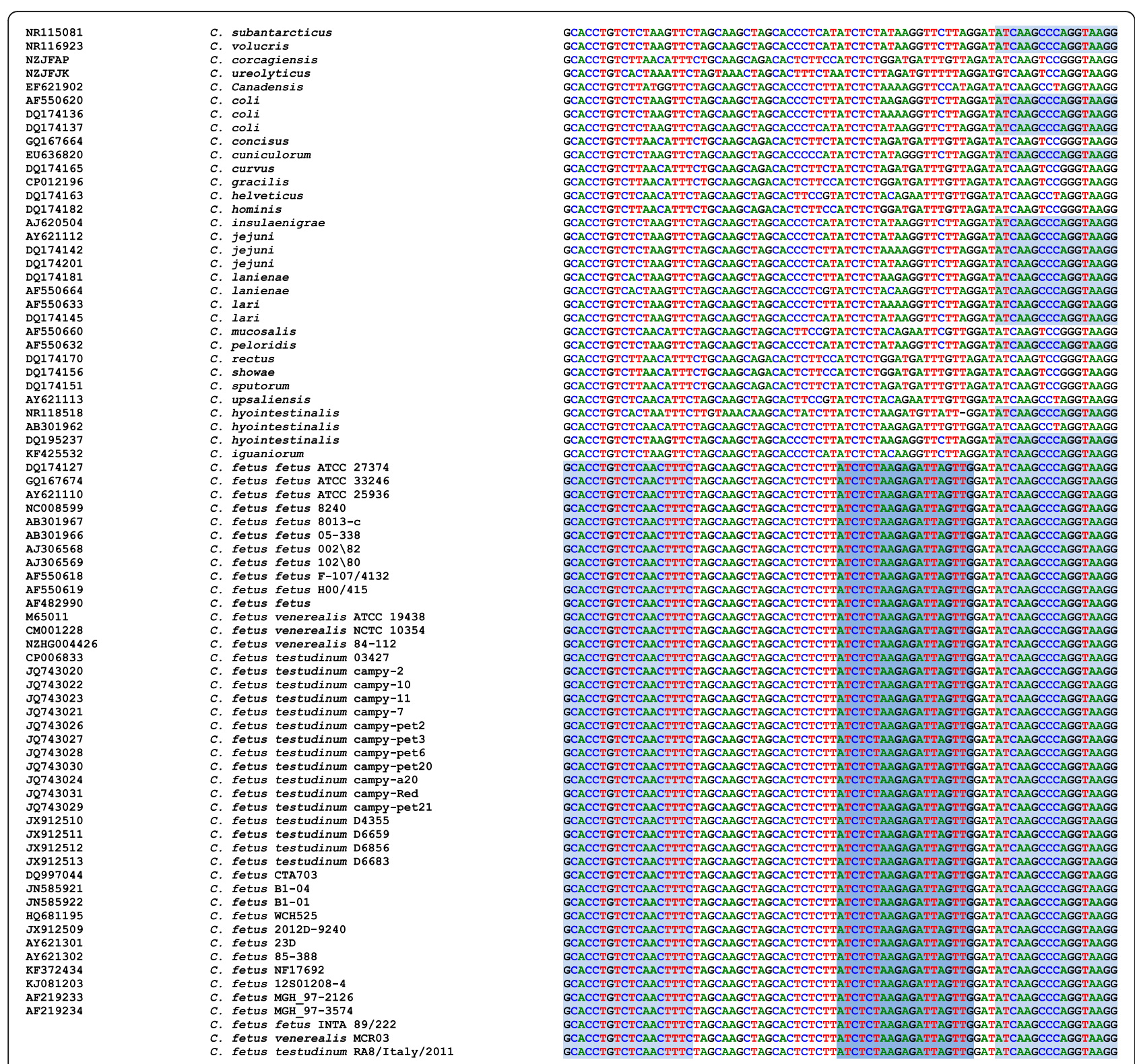

Fig. 1 Multiple alignment of partial sequences of 165 gene obtained from databases. Sequences of all species of the genus from which information is available are shown. The sequences of the primers and probe are shaded

detection protocols, like the prevention of cross contamination and the minimization of manipulation and running times. However, both end-point and real-time PCR methods described to date are designed to identify C. fetus in bovine samples and do not deal with the intra-specific genetic variability of the bacteria that is found in diverse hosts. In comparison to conventional PCR methods, real-time PCR assays provide increased sensitivity and an accurate quantification of target DNA to study the dynamics of the bacteria in different hosts and tissues. To the best of our knowledge, there is not a real-time PCR method that uses ribosomal sequences for the identification and quantification of C. fetus.
Here, we have improved the current molecular methods for $C$. fetus detection by designing a new real-time PCR assay that targets the multi-copy $16 \mathrm{~S}$ rRNA gene. The variability of these sequences within Campylobacter species supports its suitability as a target for amplificationbased methods using fluorescent probes. The inclusion in the assay of a TaqMan-MGB probe provides higher specificity, sensitivity and accuracy than traditional TaqMan probes and discriminates between sequences that differ in just one nucleotide [30-32].

Our assay was compared to the cstA gene end-point PCR proposed by Hum et al. [12] and currently used as standard for molecular diagnosis of $C$. fetus. The bovine 


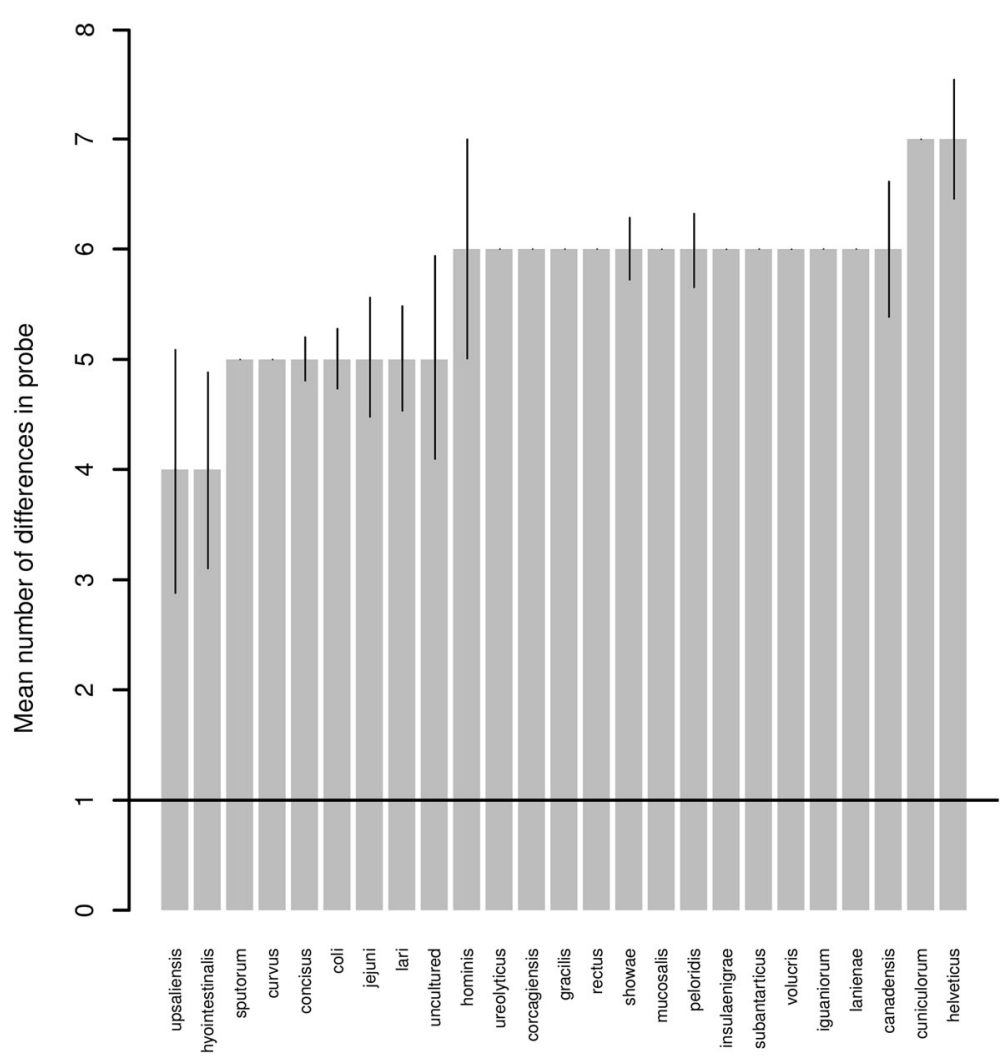

Fig. 2 Mean number of differences in probe sequence of non-C. fetus species 165 gene

sample INTA 89/222 and the reptilian RA8/Italy/2011 could not be detected by Hum's PCR (Table 1), revealing that the sensitivity of this method for bovine isolates is not complete as previously reported [12, 17, 33-36]. These isolates were confirmed as belonging to C. fetus

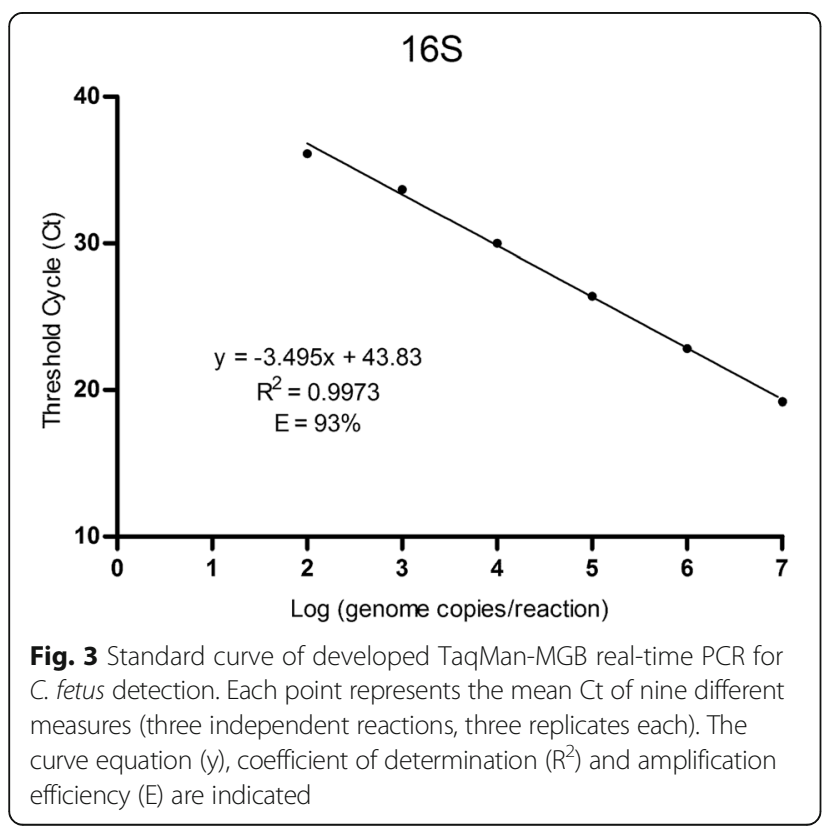

by sequencing a fragment of the 16SrRNA gene; therefore the lack of amplification of the cstA gene could be due to the absence of the target cst $A$ gene in these strains, or the presence of sequence variations that prevent the correct annealing of primers. Our attempt to amplify a larger region including Hum's PCR target region also failed, indicating the absence of this gene in these strains or an even greater sequence divergence within the $\operatorname{cst} A$ gene (data not shown). To test this hypothesis, it would be necessary to conduct the whole genome analysis of these strains. This notion is supported by the presence of several differences in Hum's primers binding sites in the complete genome of the reptilian strain C. fetus subsp. testudinum 03-427 (GenBank Acc. number NC_022759). This explains why the 13 isolates used for the description of this subspecies, and the RA8/Italy/2011 strain analyzed here, were negative for Hum's method based on the cstA gene [10]. Given the importance of this gene in the metabolism of nitrogen, and in the interaction with the host in $C$. jejuni [37], it is necessary to continue investigating its variations and possible roles in C. fetus.

Our novel real-time PCR assay detected all C. fetus tested in this study, but was negative for other Campylobacter species. The complete identity of primer and probe targets in all C. fetus strains deposited in the GenBank database (including reptilian isolates) supports that our 
Table 2 Intra- and inter-assay reproducibility for the detection of C. fetus

\begin{tabular}{|c|c|c|c|c|}
\hline \multirow[t]{2}{*}{ Genome copies/reaction } & \multicolumn{2}{|l|}{ Intra-assay variations } & \multicolumn{2}{|c|}{ Inter-assay variations } \\
\hline & Mean Ct (from - to) & $\mathrm{CV}$ (from - to) & Mean Ct & CV \\
\hline $1 \times 10^{1}$ & $-{ }^{a}$ & - & - & - \\
\hline $1 \times 10^{2}$ & $36.57-37.69$ & $0.97-2.1$ & 37.13 & 2.19 \\
\hline $1 \times 10^{3}$ & $33.68-34.11$ & $0.48-1.15$ & 33.89 & 1.05 \\
\hline $1 \times 10^{4}$ & $30-30.07$ & $0.25-0.16$ & 30.03 & 0.23 \\
\hline $1 \times 10^{5}$ & $26.37-26.46$ & $0.14-0.27$ & 26.41 & 0.26 \\
\hline $1 \times 10^{6}$ & $22.62-22.86$ & $0.18-0.7$ & 22.74 & 0.73 \\
\hline $1 \times 10^{7}$ & $19.02-19.23$ & $0.5-0.83$ & 19.12 & 0.86 \\
\hline
\end{tabular}

CV coefficient of variation of $\mathrm{Ct}$ values [\%]

${ }^{\mathrm{a}} \mathrm{Ct}$ value out of dynamic range

assay is expected to detect the currently described subspecies from diverse hosts (Fig. 1). These results indicate the excellent sensitivity and specificity of the assay. In addition, the primers and probe sequences are conserved in the 16SrRNA gene of the three subspecies (Fig. 1), in contrast with what happens with primers that amplify the cstA gene.

The assay here described has some advantages over other real-time PCR methods described in the literature. The nahE assay reported by Van der Graaf-van Bloois et al. [17] uses a TaqMan probe that provides high sensitivity and detection capability, but its quantification capability has not been ascertained using a standard curve. It is also uncertain whether this assay would detect reptilian $C$. fetus testudinum isolates, for which it was not designed, as the probe and the forward PCR primers have two mismatches each with respect to the $C$. fetus testudinum reference strain 03-427. The hybridization of primers and probes to the $n a h E$ gene could be also affected because it is embedded in a region that shows genomic rearrangements in most of the complete genome sequences available in the databases (not shown). The methodology to detect the cpn60 gene described by Chaban et al. [14] uses specific primers and SYBR green chemistry to identify $C$. fetus species, but its performance is sub-optimal in samples with low bacterial concentrations [15], such as the uncultured samples that were successfully tested in the present assay (Table 1).

\section{Conclusions}

The $16 S$ rRNA gene-targeted assay here developed is excellent for the accurate detection and quantification of C. fetus in clinical samples and pure cultures. The possibility to characterize a large number of samples in a rapid, sensitive and reproducible way makes this assays a suitable tool for routine testing and research. For these reasons, this method has the potential to become a new standard in molecular identification of $C$. fetus species.

\section{Methods}

Real-time PCR design

The assay is based on a set of primers that amplifies a 78-bp sequence of the $16 S$ rRNA gene (16SFw: $5^{\prime}-\mathrm{GC}$ ACCTGTCTCAACTTTC-3' and 16SRv: 5'-CCTTACCT GGGCTTGAT-3') and a TaqMan-MGB probe (16SPb: 5'-VIC-ATCTCTAAGAGATTAGTTG-MGB/NFQ-3'), which targets a 19-bp polymorphic region that discriminates strains of $C$. fetus from the remaining Campylobacter species and other bacteria. This polymorphic region (Fig. 1) was detected by visual inspection of over 3859 partial and complete $16 S$ rRNA gene sequences aligned with T-Coffee [38]. The constructed alignment comprised sequences from all recognized Campylobacter species and from unassigned strains belonging to the genus, which were obtained from the SILVA database [39]. An alignment of 1907 representative sequences (removing identical sequences) is shown in Additional file 1. BLAST algorithm [40] was used to check in silico the specificity of primers and probe sequences, and to evaluate the occurrence of non-specific matches within the genomes of $C$. fetus and other bacterial species.

\section{Bacterial strains: species and subspecies identification}

The real-time PCR assay was tested with a collection of C. fetus strains isolated from cattle, humans and reptiles. Two of the strains (INTA 97/C1N3 and INTA 97/608) were assayed also directly from bovine samples of placenta or vaginal mucus, without a previous isolation step. Ten additional strains from four non-fetus Campylobacter species that occasionally occur in bovine samples were used to verify the specificity of the assays (Table 1 ).

Strains were previously typed using bacteriological methods to test the assay specificity. Samples were grown in Brucella semi-solid Broth and Campylobacter selective medium under microaerophillic conditions $\left(85 \% \mathrm{H}_{2}, 5 \%\right.$ $\mathrm{O}_{2}, 10 \% \mathrm{CO}_{2}$ ) for $48 \mathrm{~h}$ at $37{ }^{\circ} \mathrm{C}$. The presumptive Campylobacter colonies were tested by catalase and oxidase tests, and grown in Brucella broth (Sigma-Aldrich, St. 
Louis, USA) with 1, 1.3, 1.5 and $1.9 \%$ glycine (SigmaAldrich), without glycine and in Brucella broth with $\mathrm{NaCl}$ and cysteine (Sigma-Aldrich) to detect $\mathrm{H}_{2} \mathrm{~S}$ production with a lead acetate paper (Sigma-Aldrich). Sodium selenite reduction test was also performed. Colonies that grew in $1 \%$ glycine were classified as $C$. fetus fetus or $C$. fetus testudinum by their positive or negative $\mathrm{H}_{2} \mathrm{~S}$ production, respectively. Glycine-sensitive colonies were assigned to the subspecies C. fetus venerealis $\left(\mathrm{H}_{2} \mathrm{~S}\right.$ negative) or $C$. fetus venerealis bv intermedius $\left(\mathrm{H}_{2} \mathrm{~S}\right.$ positive) (Table 1$)$. Out of a total of 60 strains, 25 were C. fetus fetus, 20 C. fetus venerealis, $10 \mathrm{C}$. fetus venerealis bv intermedius, one was C. fetus testudinum, and four were not analyzed.

Strains were further characterized using the multiplexPCR assays designed by Hum et al. [12] and Iraola et al. [41]. Both assays use the same species-specific primers to detect the $c s t A$ gene and different genes to identify the subspecies. The first method includes a fragment of the parA gene as a $C$. fetus venerealis marker, and the second uses a fragment of the virB11 gene (Table 1) [42].

In cases where multiplex-PCR based methods failed to identify the isolates, molecular identification of species was confirmed by sequencing a fragment of the $16 \mathrm{~S}$ rRNA gene, which was amplified using the C412F and C1288R primers described by Linton et al [21].

\section{Real-time PCR assays}

DNA was extracted from $500 \mu \mathrm{L}$ of a suspension of live bacteria in a phosphate-buffered saline $\mathrm{pH} 7.4$ solution $\left(1 \times 10^{8} \mathrm{CFU} / \mathrm{mL}\right)$, or from $1 \mathrm{~mL}$ of preputial washing or vaginal mucus. The QIAamp DNA Mini Kit (Qiagen, Hilden, Germany) was used for all DNA extractions and the DNA purity was measured as the ratio of absorbance at 260 and $280 \mathrm{~nm}$ (A260/280) using a Nanodrop 2000 (Thermo Scientific, Waltham, USA).

Real-time PCR was carried out in a $25-\mu \mathrm{L}$ reaction containing $1 \times$ TaqMan Genotyping Master Mix (Applied Biosystems, Foster City, USA), $1 \times$ Custom TaqMan SNP Genotyping Assay $(0.9 \mu \mathrm{M}$ each primer and $0.2 \mu \mathrm{M}$ probe), and $1 \mu \mathrm{L}$ genomic DNA. Thermocycling was performed on an ABIPrism 7500 (Applied Biosystems) and consisted of a $5 \mathrm{~min}$ incubation step at $50^{\circ} \mathrm{C}$, denaturation for $10 \mathrm{~min}$ at $95^{\circ} \mathrm{C}$, followed by 40 cycles of $15 \mathrm{~s}$ at $95^{\circ} \mathrm{C}$ and $1 \mathrm{~min}$ at $60{ }^{\circ} \mathrm{C}$, and a final step of $5 \mathrm{~min}$ at $70{ }^{\circ} \mathrm{C}$. Fluorescence measurements from VIC fluorophore was collected at the $5 \mathrm{~min}$ initial incubation stage, at the $60{ }^{\circ} \mathrm{C}$ step of each cycle, and at the end of the run.

\section{Standard curve generation for analytical testing}

To construct the standard curve for the ribosomal probe we generated 10 -fold serial dilutions containing $10^{\circ}-10^{7}$ genome copies/ $\mu \mathrm{L}$. Number of genome copies was determined by the following formula: $\mathrm{Y}$ (genome copies $/ \mu \mathrm{L})=$ $[X(\mathrm{~g} / \mu \mathrm{L}) \mathrm{DNA} /(\mathrm{nt}$ genome length $\times 660)] \times\left(6.022 \times 10^{23}\right)$ using the DNA concentration of the dilution $(\mathrm{X})$ and the genome size of the strain Cff 82-40 (1.77 Mb; GenBank accession number NC008599). The log dilution series of C. fetus genomes and negative controls containing nuclease-free water were tested with real-time PCR in triplicate and in three independent runs.

Standard curve was generated by plotting threshold cycle $(\mathrm{Ct})$ values per three replicates per standard dilution versus the logarithm of the bacterial genome copies to determine analytical sensitivity and efficiency of the assay. The amplification efficiency was calculated with the equation $E=\left(10^{(-1 / k)}\right)-1$, where $(k)$ is the slope of the linear regression line [43, 44]. A value of 1 corresponds to $100 \%$ amplification efficiency. The coefficient of determination $\left(R^{2}\right)$ was also assessed and was considered to be suitable when it was higher than 0.980 in a single run $[45,46]$. The coefficients of variation $(\mathrm{CVs})$ of $\mathrm{Ct}$ values were assessed separately for each standard bacterial dilution by analyzing the replicates of the same analytical run (intraassay) and the repeated analyses from different analytical runs (inter-assay).

\section{Additional files}

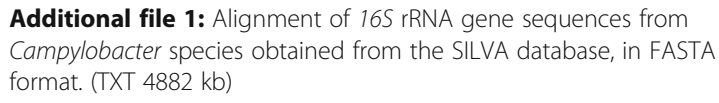

\section{Acknowledgments}

LC and Gl acknowledge support from the "Comisión Sectorial de Investigación Científica" (CSIC), and "Agencia Nacional de Investigación e Innovación" (ANII) fellowship programs from Uruguay. This work was partially financed by ANII-FSSA-2014-1-105252 Project Grant from the ANII agency.

\section{Funding}

This work was partially funded by ANII-FSSA-2014-1-105252 Project Grant from the ANII agency.

\section{Availability of data and materials \\ The datasets supporting the conclusions of this article are included within the article (and its Additional file 1).}

\section{Authors' contributions}

Gl, LC and RP conceived and designed the experiments; Gl, LC, LB, AMa, AMé, CM, GT and AV performed the experiments; Gl, LC, AMa, RP and GT analyzed the data; GI, LB, LC, FP, AP and RP contributed reagents/materials/ analysis tools; Gl, LC and RP wrote the paper. All authors revised and approved the final version of the manuscript.

\section{Competing interests}

The authors declare that they have no competing interests.

\section{Consent for publication}

Not applicable.

\section{Ethics approval and consent to participate}

This study was carried out in compliance with the veterinary best practice and the informed owner consent in the case of animal samples sent to investigation diagnostics in a Laboratory of Bacteriology. Human bacterial isolates were already part of a strain collection from a diagnostics center, therefore no ethics approval was considered necessary. 


\section{Author details}

'Sección Genética Evolutiva, Facultad de Ciencias, Iguá 4225, Montevideo 11400, Uruguay. ${ }^{2}$ Unidad de Bioinformática, Institut Pasteur Montevideo, Montevideo, Uruguay. ${ }^{3}$ Laboratorio de Bacteriología, Unidad Integrada INTA-Universidad Nacional de Mar del Plata, Balcarce, Argentina. ${ }^{4}$ Departamento de Bacteriología y Virología, Instituto de Higiene, Facultad de Medicina, Universidad de la República, Montevideo, Uruguay. ${ }^{5}$ Dipartimento di Biomedicina Comparata e Alimentazione, Università degli Studi di Padova, Padova, Italy.

\section{Received: 20 February 2016 Accepted: 6 December 2016} Published online: 15 December 2016

\section{References}

1. Man SM. The clinical importance of emerging Campylobacter species. Nat Rev Gastroenterol Hepatol. 2011;8:669-85.

2. On SLW. Isolation, identification and subtyping of Campylobacter: where to from here? J Microbiol Methods. 2013:95:3-7.

3. On SLW. Taxonomy of Campylobacter, Arcobacter, Helicobacter and related bacteria: current status, future prospects and immediate concerns. J Appl Microbiol. 2001;90:1S-15S.

4. OIE. Código sanitario para los animales terrestres. CA PITULO 11. 3. Campilobacteriosis genital bovina. 2014. p. 10-1. Spanish version.

5. Veron M, Chatelain R. Taxonomic Study of the Genus Campylobacter Sebald and Veron and Designation of the Neotype Strain for the Type Species, Campylobacter fetus (Smith and Taylor) Sebald and Veron. Int J Syst Bacteriol. 1973;23:122-34.

6. Garcia MM, Ruckerbauer GM, Eaglesome MD, Boisclair WE. Detection of Campylobacter fetus in artificial insemination bulls with a transport enrichment medium. Can J Comp Med. 1983;47:336-40.

7. Wagenaar JA, van Bergen MAP, Blaser MJ, Tauxe RV, Newell DG, van Putten JPM, Van Bergen MAP, Robert V, Van Putten JPM, Diseases M, Consultancy FZ, Birches S. Campylobacter fetus infections in humans: exposure and disease. Clin Infect Dis. 2014;58:1-26.

8. Iraola G, Betancor L, Calleros L, Gadea P, Algorta G, Galeano S, Muxi P, Greif G, Pérez R. A rural worker infected with a bovine-prevalent genotype of Campylobacter fetus subsp. fetus supports zoonotic transmission and inconsistency of MLST and whole-genome typing. Eur J Clin Microbiol Infect Dis 2015;34:1593-6.

9. Mshelia GD, Amin JD, Woldehiwet Z, Murray RD, Egwu GO. Epidemiology of bovine venereal campylobacteriosis: geographic distribution and recent advances in molecular diagnostic techniques. Reprod Domest Anim. 2010;45:e221-30.

10. Fitzgerald C, Tu ZC, Patrick M, Stiles T, Lawson AJ, Santovenia M, Gilbert MJ, van Bergen M, Joyce K, Pruckler J, Stroika S, Duim B, Miller WG, Loparev V, Sinnige JC, Fields PI, Tauxe RV, Blaser MJ, Wagenaar JA. Campylobacter fetus subsp. testudinum subsp. nov., isolated from humans and reptiles. Int J Syst Evol Microbiol. 2014:64(Pt 9):2944-8

11. Alves TM, Stynen APR, Miranda KL. Campilobacteriose genital bovina e tricomonose genital bovina : epidemiologia, diagnóstico e controle. Pesqui Veterinária Bras. 2011;31:336-44.

12. Hum S, Quinn K, Brunner J, On SL. Evaluation of a PCR assay for identification and differentiation of Campylobacter fetus subspecies. Aust Vet J. 1997;75:827-31.

13. Abril C, Vilei EM, Brodard I, Burnens A, Frey J, Miserez R. Discovery of insertion element ISCfe1: a new tool for Campylobacter fetus subspecies differentiation. Clin Microbiol Infect. 2007;13:993-1000.

14. Chaban B, Musil KM, Himsworth CG, Hill JE. Development of cpn60-based real-time quantitative $P C R$ assays for the detection of 14 Campylobacter species and application to screening of canine fecal samples. Appl Environ Microbiol. 2009;75:3055-61.

15. Chaban B, Chu S, Hendrick S, Waldner C, Hill JE. Evaluation of a Campylobacter fetus subspecies venerealis real-time quantitative polymerase chain reaction for direct analysis of bovine preputial samples. Can J Vet Res. 2012;76:166-73.

16. Selim AM, Elhaig MM, Gaede W. Development of multiplex real-time PCR assay for the detection of Brucella spp., Leptospira spp. and Campylobacter foetus. Vet Ital. 2014;50:269-75.

17. van der Graaf-van Bloois $L$, van Bergen MAP, van der Wal FJ, de Boer AG, Duim B, Schmidt T, Wagenaar JA, van Bloois LVDG. Evaluation of molecular assays for identification Campylobacter fetus species and subspecies and development of a C. fetus specific real-time PCR assay. J Microbiol Methods. 2013:95:93-7.

18. Blom K, Patton CM, Nicholson MA, Swaminathan B. Identification of Campylobacter fetus by PCR-DNA probe method. J Clin Microbiol. 1995;33:1360-2

19. Cardarelli-Leite P, Blom K, Patton CM, Nicholson MA, Steigerwalt AG, Hunter SB, Brenner DJ, Barrett TJ, Swaminathan B. Rapid identification of Campylobacter species by restriction fragment length polymorphism analysis of a PCR-amplified fragment of the gene coding for $16 \mathrm{~S}$ rRNA. J Clin Microbiol. 1996;34:62-7.

20. Kolbert CP, Persing DH. Ribosomal DNA sequencing as a tool for identification of bacterial pathogens. Curr Opin Microbiol. 1999;2:299-305.

21. Linton D, Owen RJ, Stanley J. Rapid identification by PCR of the genus Campylobacter and of five Campylobacter species enteropathogenic for man and animals. Res Microbiol. 1996;147:707-18.

22. Weisburg WG, Barns SM, Pelletier DA, Lane DJ. 165 ribosomal DNA amplification for phylogenetic study. J Bacteriol. 1991;173:697-703.

23. Wesley IV, Wesley RD, Cardella M, Dewhirst FE, Paster BJ. Oligodeoxynucleotide probes for Campylobacter fetus and Campylobacter hyointestinalis based on 165 rRNA sequences. J Clin Microbiol. 1991;29:1812-7.

24. Gorkiewicz G, Feierl G, Schober C, Dieber F, Köfer J, Zechner R, Zechner EL. Species-specific identification of campylobacters by partial 16S rRNA gene sequencing. J Clin Microbiol. 2003:41:2537-46.

25. Oyarzabal OA, Wesley TV, Harmon KM, Barbaree JM, Lauerman LH, Backert S, Conner DE. Campylobacter fetus by PCR targeting variable regions of the 16s rDNA, vol. 58. 1997. p. 61-71.

26. On SLW. Identification methods for campylobacters, helicobacters, and related organisms. Clin Microbiol Rev. 1996;9:405-22.

27. Tramuta C, Lacerenza D, Zoppi S, Goria M, Dondo A, Ferroglio E, Nebbia P, Rosati S. Development of a set of multiplex standard polymerase chain reaction assays for the identification of infectious agents from aborted bovine clinical samples. J Vet Diagn Invest. 2011:23:657-64.

28. van Bergen MA, Simons $G$, van der Graaf-van Bloois $L$, van Putten JP, Rombout J, Wesley I, Wagenaar JA. Amplified fragment length polymorphism based identification of genetic markers and novel PCR assay for differentiation of Campylobacter fetus subspecies. J Med Microbiol. 2005:54(Pt 12):1217-24.

29. Wang G, Clark CG, Taylor TM, Pucknell C, Barton C, Price L, Woodward DL, Rodgers FG. Colony multiplex PCR assay for identification and differentiation of Campylobacter jejuni, C. coli, C. lari, C. upsaliensis, and C. fetus subsp. fetus. J Clin Microbiol. 2002:40:4744-7.

30. Alonso R, Mateo E, Cisterna R. Detection of parC mutations in Streptococcus pneumoniae by Real-time PCR and Taqman-MGB probes. J Microbiol Methods. 2007:69:214-7.

31. Kutyavin IV, Afonina IA, Mills A, Gorn W, Lukhtanov EA, Belousov ES, Singer MJ, Walburger DK, Lokhov SG, Gall AA, Dempcy R, Reed MW, Meyer RB, Hedgpeth J. 3'-minor groove binder-DNA probes increase sequence specificity at PCR extension temperatures. Nucleic Acids Res. 2000;28:655-61.

32. Rousselon N, Delgenès JP, Godon JJ. A new real time PCR (TaqMan ${ }^{\oplus} \mathrm{PCR}$ ) system for detection of the 16S rDNA gene associated with fecal bacteria. J Microbiol Methods. 2004;59:15-22.

33. Schmidt T, Venter EH, Picard JA. Evaluation of PCR assays for the detection of Campylobacter fetus in bovine preputial scrapings and the identification of subspecies in South African field isolates. J S Afr Vet Assoc. 2010;81:87-92.

34. Schulze F, Bagon A, Müller W, Hotzel H. Identification of Campylobacter fetus subspecies by phenotypic differentiation and PCR. J Clin Microbiol. 2006:44:2019-24.

35. van der Graaf-van Bloois L, Miller WG, Yee E, Rijnsburger M, Wagenaar JA, Duim B. Inconsistency of phenotypic and genomic characteristics of Campylobacter fetus subspecies requires reevaluation of current diagnostics. J Clin Microbiol. 2014;52:4183-8.

36. Willoughby K, Nettleton PF, Quirie M, Maley MA, Foster G, Toszeghy M, Newell DG. A multiplex polymerase chain reaction to detect and differentiate Campylobacter fetus subspecies fetus and Campylobacter fetus subspecies venerealis: use on UK isolates of C. fetus and other Campylobacter spp. J Appl Microbiol. 2005;99:758-66

37. Rasmussen JJ, Vegge CS, Frøkiær H, Howlett RM, Krogfelt KA, Kelly DJ, Ingmer H. Campylobacter jejuni carbon starvation protein A (CstA) is involved in peptide utilization, motility and agglutination, and has a role in stimulation of dendritic cells. J Med Microbiol. 2013;62:1135-43.

38. Notredame C, Higgins DG, Heringa J. T-coffee: a novel method for fast and accurate multiple sequence alignment. J Mol Biol. 2000;302:205-17. 
39. Quast C, Pruesse E, Yilmaz P, Gerken J, Schweer T, Yarza P, Peplies J, Glockner FO. The SILVA ribosomal RNA gene database project: improved data processing and web-based tools. Nucleic Acids Res. 2013;41:D590-6.

40. Altschul SF, Gish W, Miller W, Myers EW, Lipman DJ. Basic local alignment search tool. J Mol Biol. 1990;215:403-10.

41. Iraola G, Hernández M, Calleros L, Paolicchi F, Silveyra S, Velilla A, Carretto L, Rodríguez E, Pérez R. Application of a multiplex PCR assay for Campylobacter fetus detection and subspecies differentiation in uncultured samples of aborted bovine fetuses. J Vet Sci. 2012;13:371-6.

42. Moolhuijzen PM, Lew-Tabor AE, Wlodek BM, Agüero FG, Comerci DJ, Ugalde RA, Sanchez DO, Appels R, Bellgard M. Genomic analysis of Campylobacter fetus subspecies: identification of candidate virulence determinants and diagnostic assay targets. BMC Microbiol. 2009;9:86-97.

43. Ginzinger DG. Gene quantification using real-time quantitative PCR: an emerging technology hits the mainstream. Exp Hematol. 2002;30:503-12.

44. Pfaffl MW. A new mathematical model for relative quantification in real-time RT-PCR. Nucleic Acids Res. 2001;29:e45.

45. Buh Gasparic M, Cankar K, Zel J, Gruden K. Comparison of different real-time PCR chemistries and their suitability for detection and quantification of genetically modified organisms. BMC Biotechnol. 2008;8:26

46. Bustin SA, Nolan T. Pitfalls of quantitative real-time reverse-transcription polymerase chain reaction. J Biomol Tech. 2004;15:155-66.

Submit your next manuscript to BioMed Central and we will help you at every step:

- We accept pre-submission inquiries

- Our selector tool helps you to find the most relevant journal

- We provide round the clock customer support

- Convenient online submission

- Thorough peer review

- Inclusion in PubMed and all major indexing services

- Maximum visibility for your research

Submit your manuscript at www.biomedcentral.com/submit
Biomed Central 